Research Article

\title{
Small Pilot Tunnel Advance and Step Reverse Expansion in Super-Large-Section Tunnel Excavation
}

\author{
Bole Sun $\mathbb{C D}^{1,2}$ Xiaorong Tang, ${ }^{3}$ Yongyi He $\mathbb{C D}^{1,2}$ and Mingnian Wang ${ }^{1}$ \\ ${ }^{1}$ College of Civil Engineering, Southwest Jiaotong University, Chengdu 610065, China \\ ${ }^{2}$ China Railway Third Bureau Group Co., Ltd., Taiyuan 030001, China \\ ${ }^{3}$ Hebei Oriental University, Langfang 065001, China \\ Correspondence should be addressed to Bole Sun; 340106@my.swjtu.edu.cn
}

Received 23 September 2021; Accepted 20 November 2021; Published 11 December 2021

Academic Editor: Gan Feng

Copyright $\odot 2021$ Bole Sun et al. This is an open access article distributed under the Creative Commons Attribution License, which permits unrestricted use, distribution, and reproduction in any medium, provided the original work is properly cited.

\begin{abstract}
Collapse of the vault and numerous other safety accidents often occur during the construction process of large-section tunnels. The utilization of a small pilot tunnel and a step reverse expansion construction methodology is proposed based on conventional construction methods to explore safe construction technology. First, a theoretical analysis combined with on-site monitoring parameters was conducted. It showed that the maximum displacement of the tunnel surrounding rock was $0.027 \mathrm{~m}$ during the elastic stage and increased to $0.031 \mathrm{~m}$ during the strength limit stage. The overall surrounding rock deformation does not have a noticeable impact on tunnel safety. A numerical simulation model of the small pilot tunnel advancement and step reverse expansion method was established. Simulation results showed that the first two excavation steps caused $89.6 \%$ of the total overlining strata subsidence, and the use of a small pilot tunnel advancement and step reverse expansion method can enhance the tunnel support. The tunnel surrounding rock was adequately stabilized after using this excavation method and provides the in-situ conditions for expanding the pilot tunnel to the large-section tunnel. The proposed method was adopted in an actual engineering project. It protected the subsequent construction of the main tunnel and decreased construction time, saving construction costs while ensuring safety, reducing construction risks, and improving production efficiency. This research can guide similar tunneling projects.
\end{abstract}

\section{Introduction}

With the rapid development of the global social economy and logistics, traditional small-section tunnels are no longer suitable for the increasing traffic. In the current tunnel construction, the excavation of large cross section or superlarge cross section is becoming common and provides improved traffic flow [1-4]. However, there are many problems in the construction of extra-large-section tunnels. During and after the excavation process for these tunnels, stress release occurs too fast, and displacement is often not controlled in time, resulting in catastrophes. There are often vault collapses, temporary support offsets, and disaster problems such as deformation of the initial support $[5,6]$. To ensure the safety of the tunnel and facilitate construction and operation, it is vital to tunnel excavation method design for a specific environment.
The excavation methods for superlarge sections include the double sidewall pilot method, Cross Diaphragm method (CRD method), step excavation method, arc pilot method, and others [7-10]. Numerous studies have been conducted on the mechanical properties and excavation methods of surrounding rock. A formula for estimating the surrounding rock pressure related to the tunnel burial depth, filling, and elapsed time was proposed by Bhawani Singh et al. [11]. Goel [12] proposed a relationship between the surrounding rock pressure and RCR (rock condition rating) system. The relationship between the pressure of the surrounding rock and the number of rock systems under squeezed and nonsqueezed conditions was obtained by Goel [13]. Barton proposed the Q system classification [14]. Bienia proposed the calculation formula for predicting surrounding rock pressure in the RMR classification [15]. Wang et al. [16] 
showed that tectonic stress greatly influences the bearing capacity, failure form, and displacement law of a three-lane highway tunnel. Concurrently, Fliegner [17] also obtained a similar conclusion. Li and Wang [18] explained large-span highway tunnels' design and construction technology by introducing the design, construction, monitoring, and measurement; they provided the supporting scientific research conducted on the Tieshanping and Huashan roads. Wang et al. [19] monitored the displacement of surrounding rock, the shear force of the initial support, the bending moment, and the dynamic changes of the bolt axial force. They outlined the problems that easily occur during the construction of large-span tunnels and their corresponding solutions. Jiang et al. [20] recommended using a three-center circular curved wall section and determined the support and lining parameters and the excavation steps.

Huang et al. [21] took the Yabao tunnel as an example, introduced the geological engineering conditions, section form, structural design, and construction plan in detail, and conducted research on construction technology and mechanical behavior. Based on the monitoring results, Xia et al. [22] analyzed the deformation and force characteristics of the surrounding rock and support system of the tunnel. They pointed out the time and space range affected by the excavation of the small clear distance tunnel and the best time for tunnel lining support, providing a basis for the optimization of the protection system. Sun et al. [23] used FLAC software to compare and analyze the influence of Center Diaphragm (CD) and bench methods on the deformation and plastic zone of the surrounding rock. Huang [24] analyzed the general design of the Longtoushan Tunnel and explained the construction method of double-side heading pit in the surrounding rock section of grades IV and V and the step construction method of grades II and III surrounding rock section. They obtained the double-side heading pit of a large-span tunnel. Li and Kang [25] summarized several problems in constructing large-section tunnels and compared the advantages and disadvantages of different excavation methods.

These studies have achieved rich results in tunnel excavation. A different excavation sequence can lead to different types and extents of deformation for the same construction method. This is closely related to the tunnel instability disaster caused by excavation. The stability of tunnel surrounding rock is directly related to the physical and mechanical properties of the rock, geological environment, tunnel excavation method, construction sequence, excavation rate, amongst other parameters. Studies have shown that temperature impacts the physical and mechanical properties of rocks [26-32]. Research on coal mining concluded that the coal excavation rate and the burial depth impact its physical and mechanical properties $[33,34]$. It can be seen that the stability of rock is the result of the comprehensive action of complex factors. However, in terms of construction methods, at present, the principle of construction methods has not been thoroughly studied.

Differing from the conventional tunnel support method, a small pilot tunnel and step reverse expansion provide information on the in-situ conditions for the construction of the main tunnel. In this method, a small pilot tunnel is first constructed. Then we use reverse expansion with controlled blasting. These methodologies reduce the excavation section and reduce safety accidents. This paper took a super-large cross section tunnel as an engineering example, comprehensively analyzed the environment of the tunnel, and explored suitable methods for excavation. Based on summarizing traditional methods, we developed a new excavation method. The adopted excavation and supporting method have achieved excellent engineering and economic benefits. This research provides a guideline for similar tunneling engineering.

\section{Theoretical Analysis}

Without maintenance, the surrounding rock is in an elastic or elastoplastic state when the stress is redistributed after the tunnel excavation. If it is in a plastic state, the tunnel collapses. Therefore, when the surrounding rock cannot satisfy the self-stability, it is necessary to take appropriate support and reinforcement measures to achieve a balance. This section analyzes a circular tunnel in the boundary stress field with equal pressure in all directions to investigate the deformation state of the surrounding rock of a tunnel without support.

2.1. Elastic State. The Hangzhou Purple Tunnel (Zijingang Road to ZhijiangLu) project, constructed by the China Railway Three Bureaus Group Co., Ltd., is located near the intersection of Zijin Port Road and Xixi Road in the West Lake District of Hangzhou City. The theoretical calculation is based on this engineering project.

The geometry of the tunnel has a width of $25.0 \mathrm{~m}$, a height of $17.4 \mathrm{~m}$, and an area of $350.0 \mathrm{~m}^{2}$. The design and construction method is an eight-step excavation of the double-sided pilot pit with temporary support. When the maximum stress in the surrounding rock of the tunnel does not reach its elastic limit, the surrounding rock is not damaged and is in an elastic state. The basic theory of elastic mechanics was used to analyze this state. The circular tunnel was considered an axisymmetric problem. Therefore, it was solved by applying the basic solution method of elastic theory. According to the theory of elastic mechanics, the stress and strain of the surrounding rock in an elastic state are reversible. Assuming that the radial support force under the same conditions is artificially applied, it can restore the rock mass to a state of natural stress and strain.

If the surrounding rock is in an elastic state, maximum displacement occurs around the tunnel. According to the mechanical parameters of the surrounding rock of the tunnel, where $a$ is $10 \mathrm{~m}, E$ is $70 \mathrm{MPa}, \mu$ is 0.2 , and $P_{0}$ is $0.16 \mathrm{MPa}$, the maximum displacement can be expressed as

$$
\Delta u_{r}=\frac{1+\mu}{E} \times \frac{a^{2}}{a} p_{0}=\frac{1+0.2}{70} \times \frac{10^{2}}{10} \times 0.16 \approx 0.027 \mathrm{~m}
$$

The shrinkage of the tunnel section is calculated to be about $1.7 \mathrm{~m}^{2}$, which accounts for $\sim 0.5 \%$ of the total area of 
the excavated tunnel. Therefore, when the surrounding rock of the tunnel is in an elastic state, the amount of deformation is negligible, and it does not interfere with the normal excavation of the tunnel.
2.2. Elastoplastic Stage. When the surrounding tunnel rock is at its strength limit, there is a specific plastic zone but no obvious deformation in the surrounding rock. The elastoplastic limit equilibrium theory was used to analyze this phenomenon [35]:

$$
\left.\begin{array}{c}
\sigma_{r}^{e}=p_{0}\left(1-\frac{a^{2}}{r^{2}}\right)+\left[c \times \operatorname{ctg} \varphi\left(\frac{R_{p}}{a}\right)^{2 \sin \varphi / 1-\sin \varphi}-c \times \operatorname{ctg} \varphi\right] \frac{a^{2}}{r^{2}} \\
\sigma_{\theta}^{e}=p_{0}\left(1+\frac{a^{2}}{r^{2}}\right)-\left[c \times \operatorname{ctg} \varphi\left(\frac{R_{p}}{a}\right)^{2 \sin \varphi / 1-\sin \varphi}-c \times \operatorname{ctg} \varphi\right] \frac{a^{2}}{r^{2}}
\end{array}\right\},
$$

where $\sigma_{\theta}^{e}$ is the circumferential stress in the elastic zone of the tunnel surrounding rock, $\sigma_{r}^{e}$ is the radial stress in the elastic zone of the surrounding rock of the tunnel, $\sigma_{\theta}^{p}$ is the circumferential stress in the plastic zone of tunnel surrounding rock, $\mu_{r}$ is the radial displacement of the surrounding rock of the tunnel, $\sigma_{r}^{p}$ is the radial stress in the plastic zone of tunnel surrounding rock, $R_{P}$ is the radius of the plastic zone of the surrounding tunnel rock, and $u$ is the displacement of the tunnel.

Bring in parameters: $a$ is $10 \mathrm{~m}, \mu$ is $0.2, E$ is $70 \mathrm{Mpa}, P_{0}$ is $0.16 \mathrm{MPa}, \varphi$ is $52^{\circ}$, and $C$ is $0.9 \mathrm{MPa}$; then, the radius of the plastic zone is $2.67 \mathrm{~m}$. The displacement at the outer boundary of the plastic zone is $0.031 \mathrm{~m}$. The maximum displacement around the tunnel is $0.008 \mathrm{~m}$.

The overall reduction of the tunnel section is about $0.5 \mathrm{~m}^{2}$, about $0.1 \%$ of the total area. Through the analysis of the tunnel in the elastic stage and elastoplastic stages, the surrounding rock is in a complete state under this excavation method. The deformation of the surrounding rock is within a stable range, and the overall deformation is minimal and does pose a threat to the normal production of tunnel driving. The theoretical analysis provides a basis for understanding the mechanical condition of the tunnel surrounding rocks, thus proposing proper supporting measures to achieve an optimized excavation goal. A numerical simulation method is established to investigate the proposed excavation methodology based on the calculation conclusions.

\section{Numerical Calculation}

3.1. Small Pilot Tunnel and Step Reverse Expansion. After comparing conventional excavation methods, the construction technology of a small pilot tunnel and step reverse expansion excavation is proposed. The construction technology consists of constructing a small pilot tunnel construction first performed with the up-and-down step method. After the pilot tunnel construction is completed, the reverse expansion construction is performed with controlled blasting construction with a pressure roof behind the trough and diagonal bracing reinforcement for the temporary support. When the inverted arch is constructed, the temporary support will be removed (Figure 1).

Construction steps are as follows:

(1) Excavate section (1), and implement initial support and temporary steel frame.

(2) After the excavation of section (1), the excavation of section (2) is reversely expanded, and the initial support and temporary support are reinforced.

(3) After lagging by a distance of $2 \sim 3 \mathrm{~m}$, section (3) is excavated, and the initial support is implemented.

(4) According to the monitoring and measurement results, the temporary steel arch frame is partially dismantled, and section (4) is excavated. The initial support base surface of the invert is cleaned, and the waterproof board is laid. Finally, the invert is poured. 


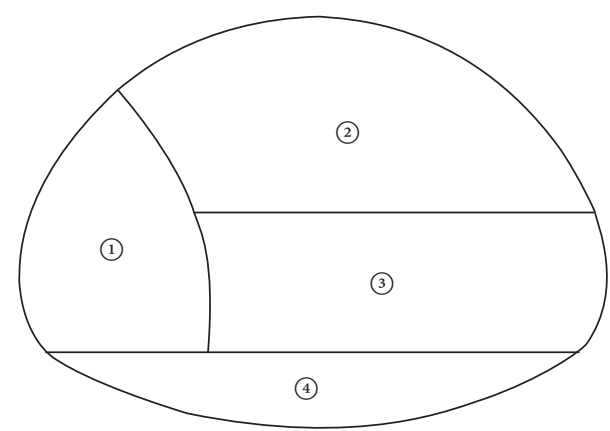

FIgURE 1: Construction sequence of sections of the super-largesection tunnel.

After the invert is initially set, the invert is poured and filled to the designated elevation.

(5) The initial support base surface of the arch wall is cleared, and a ring and longitudinal drainage system are set up. Finally, the waterproof boards are laid. According to the analysis of the monitoring measurement results, after the surrounding rock and the initial support deformation are stabilized, a second lining is poured (the arch wall lining is constructed in one piece).

3.2. Numerical Model. The technical feasibility of the construction of the small pilot tunnel and the step reverse expansion is analyzed in this section. The Midas GTS software was used for calculation. Due to the need to consider the nonlinear material characteristics of the surrounding rock and the two-dimensional state of the construction steps of tunnel excavation, a two-dimensional model was established based on the geological data parameters provided by the survey report and the relative position of the tunnel. The tunnel is $24 \mathrm{~m}$ wide and $16.31 \mathrm{~m}$ high, and at a depth of $68 \mathrm{~m}$. The model size is $167 \mathrm{~m}$ wide and $123 \mathrm{~m}$ high. It has three layers of soil, consisting of miscellaneous fill, moderately weathered siltstone, and slightly weathered siltstone. The soil properties are shown in Table 1, which are obtained from the laboratory experiments of the project.

\subsection{Numerical Analysis of Construction Feasibility.} According to the construction step diagram, the numerical analysis of the construction steps of the small pilot tunnel was first simulated, followed by the gradual step counterexpansion excavation. Figure 2 shows the model establishment. In this model, 1,369,174 blocks with $1,540,541$ nodes were created to model the rock mass. The failure criterion used was the Mohr-Coulomb Failure Criterion. The calculation focused on the following four key construction steps: the completion of the excavation and support of the left pilot tunnel, the completion of the excavation of the upper step, the completion of the excavation of the intermediate step, and the completion of the second lining construction of the invert excavation. All numerical calculation results were extracted according to the above four key steps. The following focuses on extracting the calculation results from three representative key construction steps in the vault settlement, structural deformation and stress, stratum stress distribution, and conducting corresponding theoretical analysis.

Figure 3 shows the cloud diagram of the vault settlement caused by the key steps of the small pilot tunnel and the reverse expansion of the steps.

The deformation maps in Figure 3 indicate that the first excavation has the most significant disturbance across the entire stratum. In the first step, the deformation reaches $2.3 \mathrm{~mm}$, and there is almost no dome deformation. With the second step of excavation, the maximum deformation of the top is $4.6 \mathrm{~mm}$, and there is obvious deformation of the vault, reaching $\sim 2.3 \mathrm{~mm}$. The subsequent excavation deformations are all small. The maximum deformation is only $5.2 \mathrm{~mm}$ when the excavation is completed, and the maximum deformation of the vault is $2.6 \mathrm{~mm}$, mainly concentrated on the top of the tunnel. In this construction, the deformation rate of the tunnel is different during each step of the excavation. Table 2 in the following contains the specific analysis.

The formation stress distribution of each key construction sequence is shown in Figure 4. The stress distribution of the second liner is shown in Figure 5 .

The numerical simulation results indicate that the maximum tensile stress is concentrated in the corner of the excavation, which is easily damaged. The tensile stress area increases during the stair construction. As construction progresses, the stress changes are not overly significant. Therefore, after the tunnel is excavated, the forces in other areas are relatively uniform except for the phenomenon of stress concentration at several inflection points. The force on the secondary lining is significantly smaller than the force on the surrounding rock.

The first step of constructing the small pilot tunnel and the step reverse expansion method is $2.3 \mathrm{~mm}$. With the second step of excavation, the maximum deformation of the top is $4.6 \mathrm{~mm}$, and the deformation of the vault reaches $\sim 2.3 \mathrm{~mm}$. The deformation is more prominent, accounting for $45.2 \%$ and $44.4 \%$ final ratio settlement values, respectively. Therefore, during the construction of the small pilot tunnel and the step reverse expansion method, the advance support should be strengthened, especially during the step excavation process, due to the excavation. As the cross section increases, advanced prereinforcement should be done even more.

\section{Engineering Application}

To reduce the secondary impact caused by the expansion of the tunnel on the surrounding rock of the large section, the steel frame on one side of the sidewall of the small pilot tunnel is used for the permanent support side of the large section, and the initial support on the other side is temporary, as shown in Figure 6. Small pilot tunnels are generally set as near-circular tunnels. Near-circular tunnels have better control of the maximum principal stress and deformation of the surrounding rock. The initial support is relatively strong, and the deformation after support is 
TABLE 1: Tunnel geotechnical properties.

\begin{tabular}{lcccccc}
\hline Soil category & $\begin{array}{c}\text { Layer thickness } \\
(\mathrm{m})\end{array}$ & $\begin{array}{c}\text { Density } \\
\left(\mathrm{kN} / \mathrm{m}^{3}\right)\end{array}$ & $\begin{array}{c}\text { Elastic modulus } \\
\left(\mathrm{kN} / \mathrm{m}^{3}\right)\end{array}$ & $\begin{array}{c}\text { Cohesion } \\
(\mathrm{kPa})\end{array}$ & $\begin{array}{c}\text { Internal friction } \\
\text { angle }\left(^{\circ}\right)\end{array}$ & $\begin{array}{c}\text { Poisson's ratio } \\
\text { Miscellaneous fill }\end{array}$ \\
$\begin{array}{l}\text { Moderately weathered } \\
\text { siltstone }\end{array}$ & 70 & 18.8 & 8 & 20.00 & 16.40 & 0.29 \\
$\begin{array}{l}\text { Slightly weathered } \\
\text { siltstone }\end{array}$ & 50 & 26.9 & 70 & 9210 & 52.00 & 0.20 \\
\hline
\end{tabular}

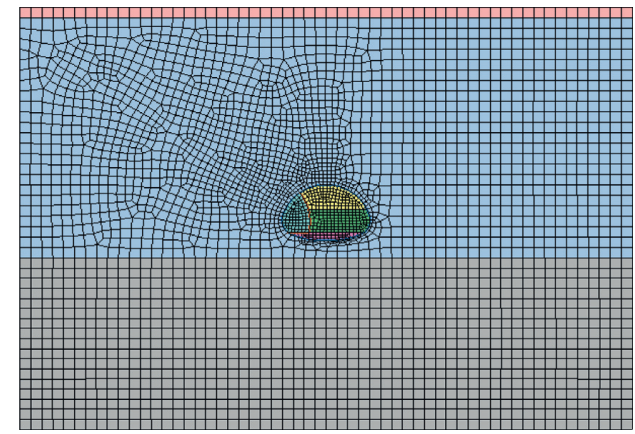

Figure 2: Numerical model grid.

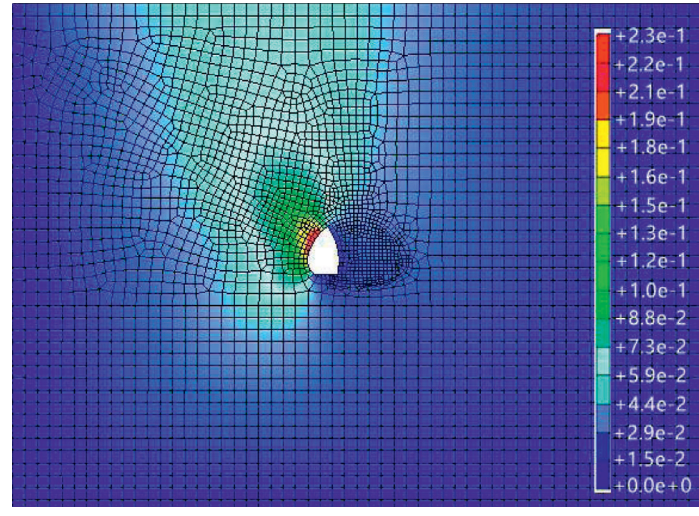

(a)

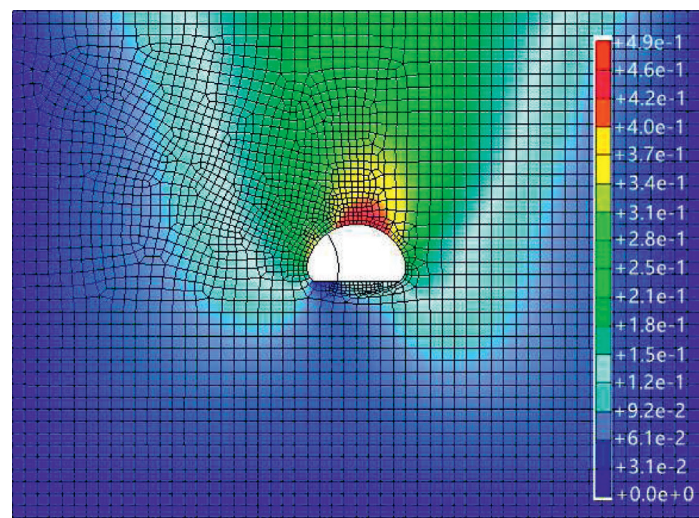

(c)

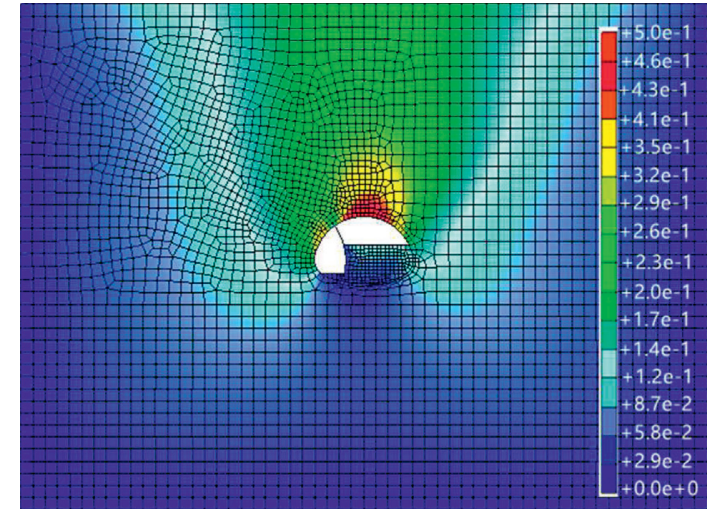

(b)

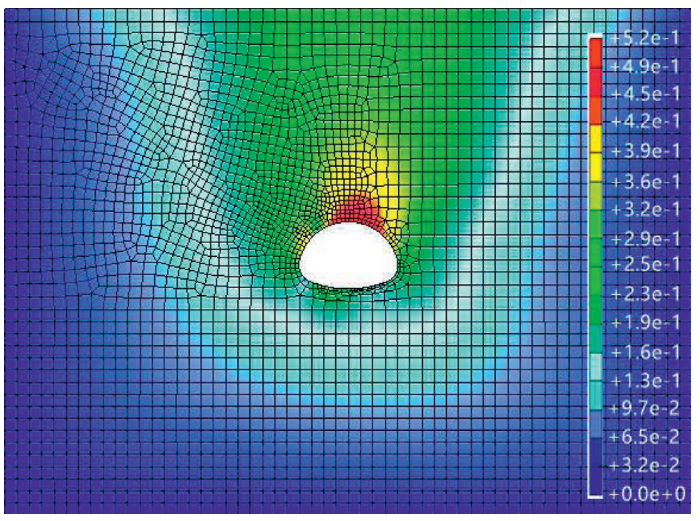

(d)

FIGURE 3: Settlement cloud diagram caused by the key steps of the double-side pilot pit. (a) Completion of the left pilot tunnel. (b) Completion of the upstairs. (c) Completion of the intermediate step. (d) All construction completed. 
TABle 2: Maximum settlement value of each key construction sequence.

\begin{tabular}{lccc}
\hline Key construction steps & $\begin{array}{c}\text { Maximum settlement value } \\
(\mathrm{mm})\end{array}$ & $\begin{array}{c}\text { Percentage of } \\
\text { settlement } \\
\text { value (\%) }\end{array}$ & $\begin{array}{c}\text { Accumulated percentage of settlement value } \\
(\%)\end{array}$ \\
\hline $\begin{array}{l}\text { Excavation of the left pilot } \\
\text { tunnel }\end{array}$ & 2.34 & 45.2 & 45.2 \\
Excavation of the upstairs & 4.64 & 44.4 & 89.6 \\
Excavation of the middle stairs & 4.91 & 5.2 & 94.8 \\
Invert excavation & 5.02 & 2.1 & 96.9 \\
Second lining & 5.18 & 3.1 & 100 \\
\hline
\end{tabular}

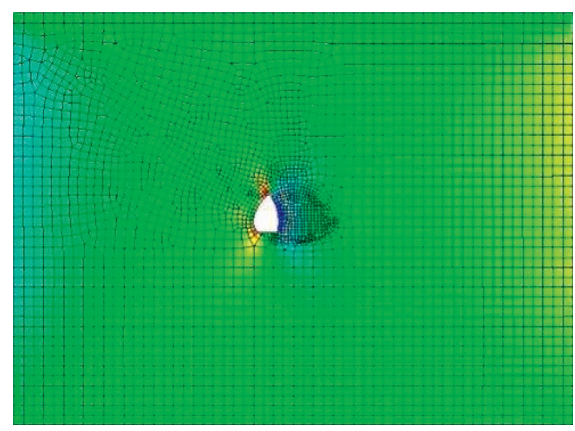

(a)

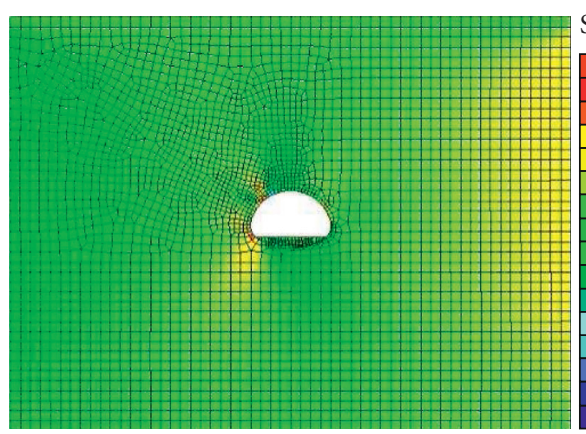

(c)

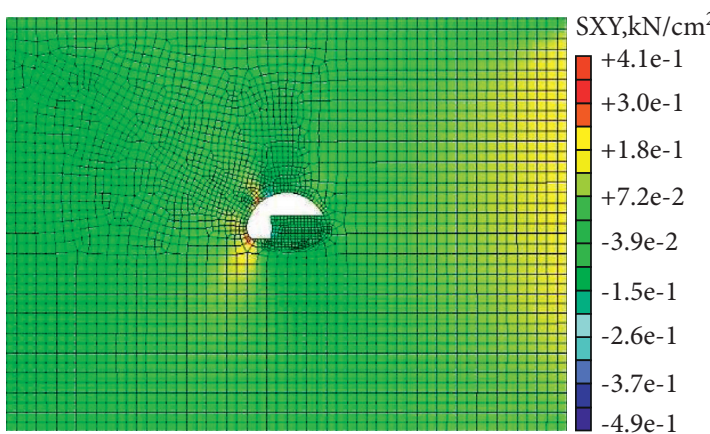

(b)

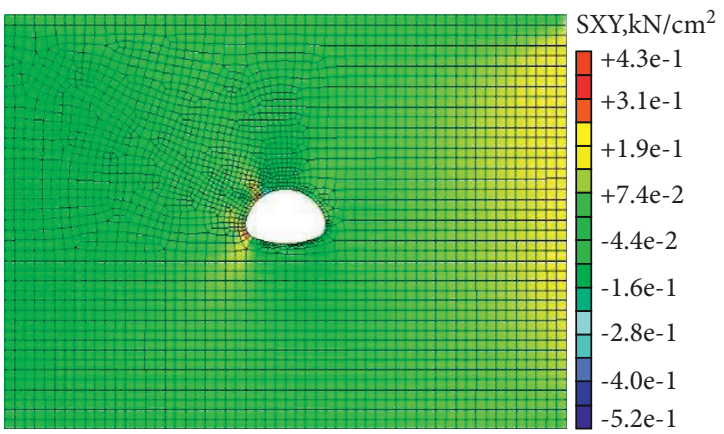

(d)

Figure 4: Small pilot tunnel first and step reverse expansion excavation. (a) Completion of the left pilot tunnel. (b) Completion of the upstairs. (c) Completion of the middle step. (d) All construction is completed.

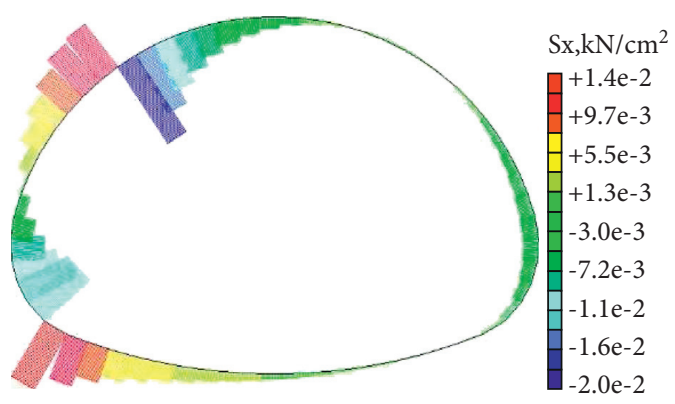

FIGURE 5: Stress distribution cloud diagram of the second lining.

negligible. On the permanent support side of the small pilot tunnel, using the general tunnel support method, prestressed bolts are added to enhance the stability of the surrounding rock.

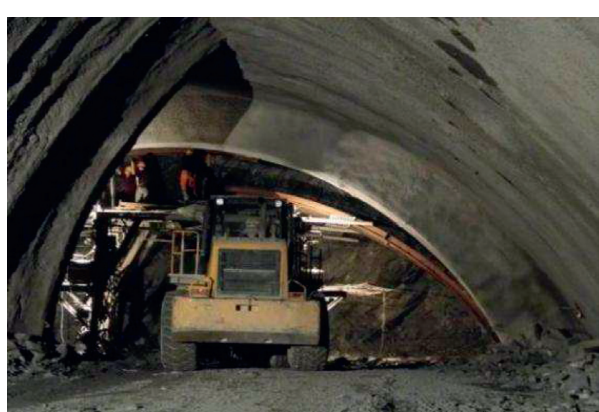

FIgURE 6: Horizontal expansion and excavation of pilot tunnel construction completed.

4.1. Construction Technology of Reverse Excavation of Bench. After constructing the small pilot tunnel, the expansion was divided into up and down step method construction, as 


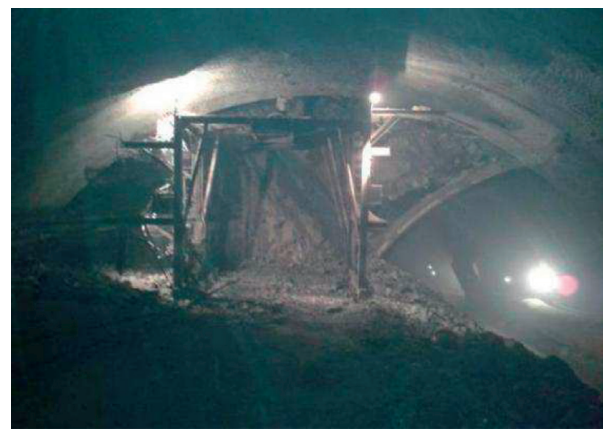

FigURE 7: Field experiment diagram of the reverse bench excavation project.
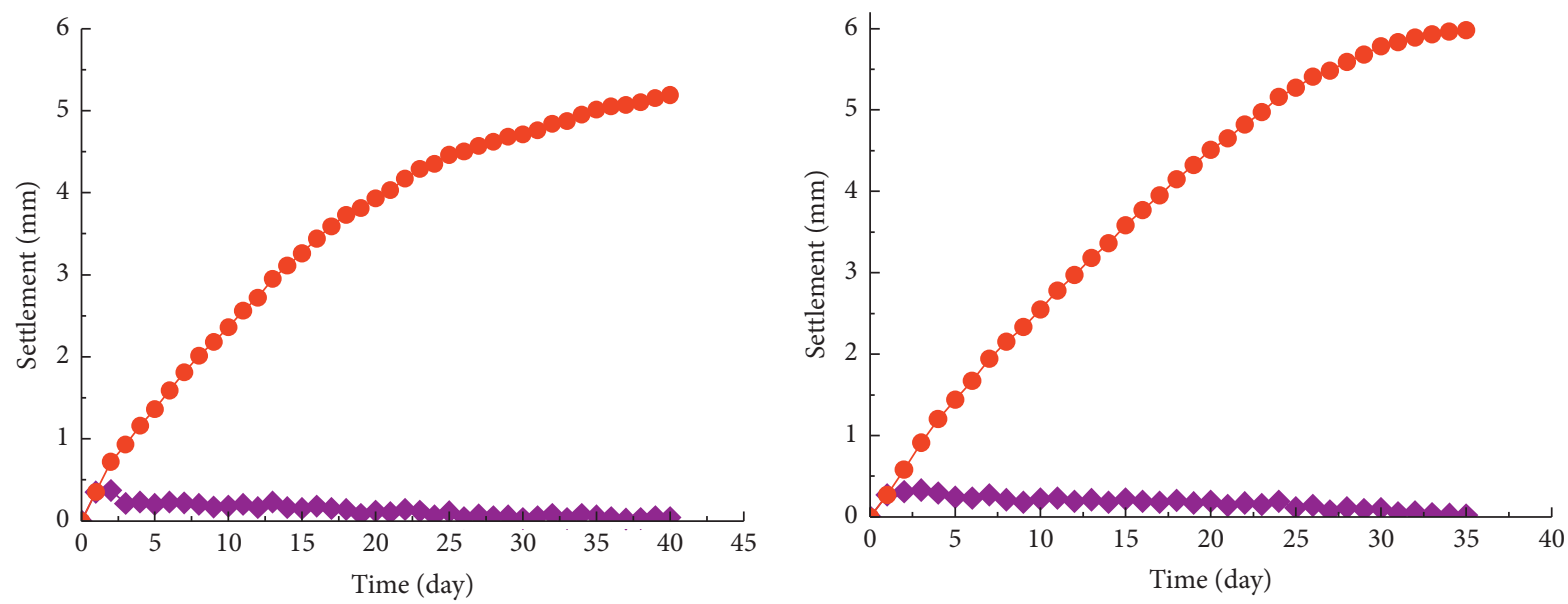

- Totle settlement

- Totle settlement

$\checkmark$ Day settlement

$\checkmark$ Day settlement

(a)
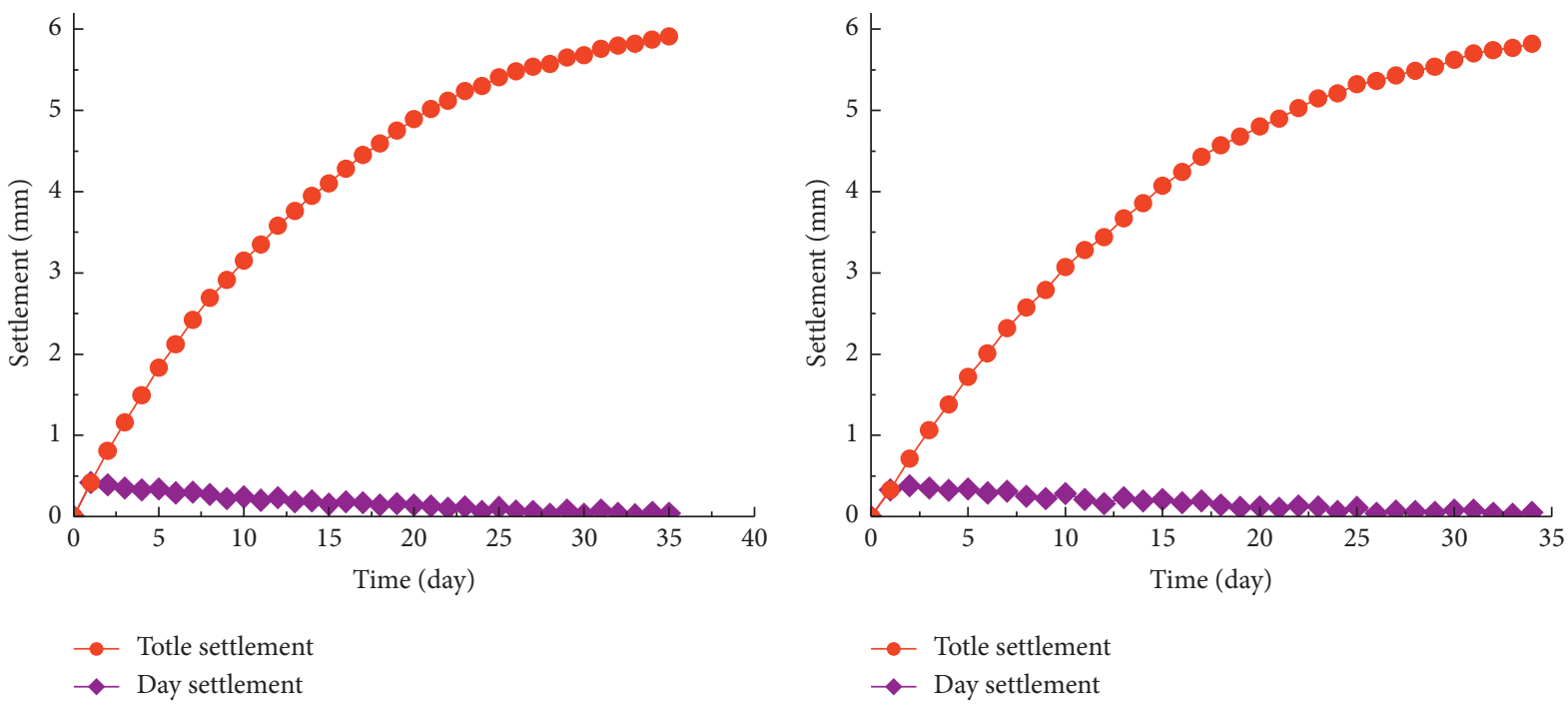

(c)

(d)

Figure 8: Continued. 


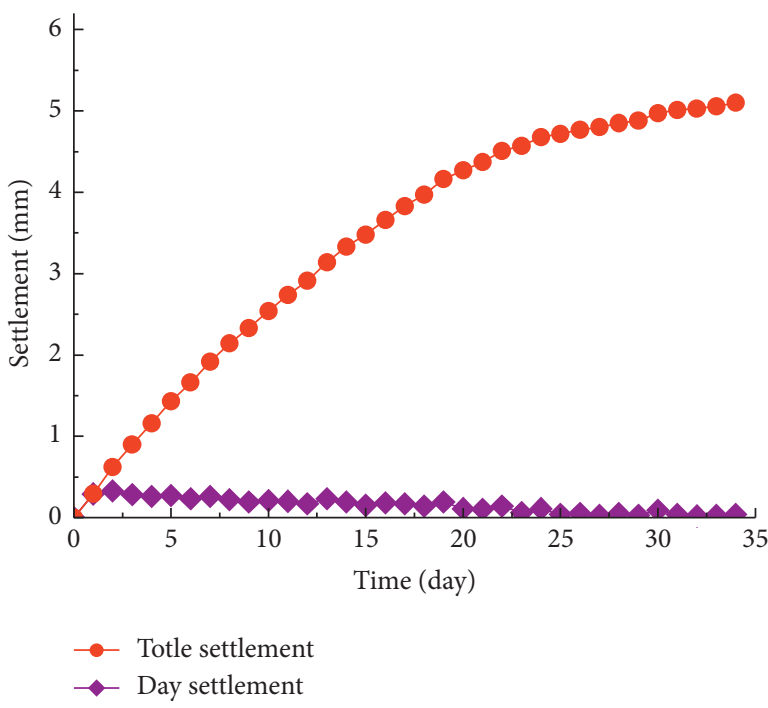

(e)

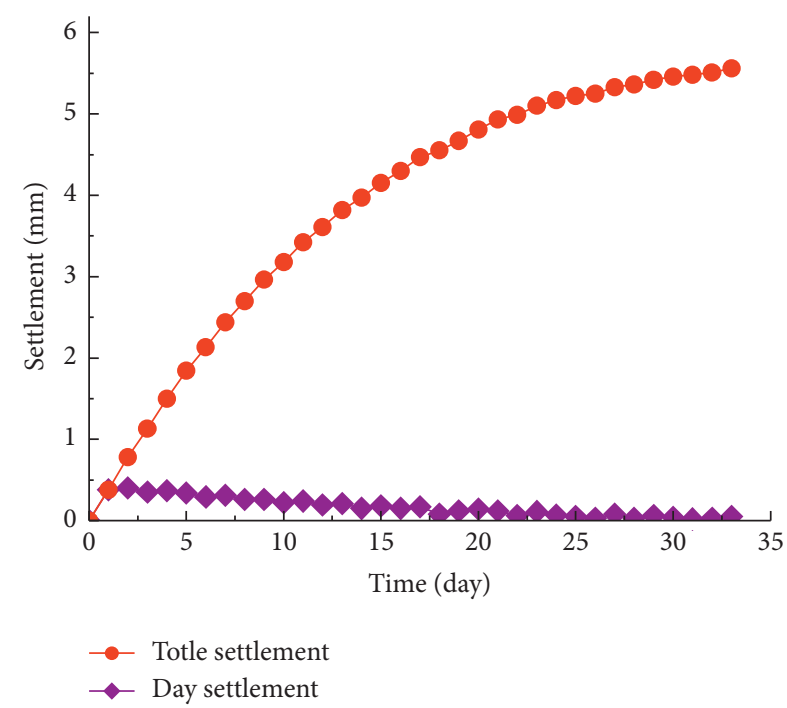

(f)

FIGURE 8: Settlement monitoring of the six monitoring points with daily and cumulative deformation. (a) Monitoring point 1. (b) Monitoring point 2. (c) Monitoring point 3. (d) Monitoring point 4. (e) Monitoring point 5. (f) Monitoring point 6.

shown in Figure 7. The upper steps were constructed by controlled blasting. The temporary support was not removed during excavation, and 18 diagonal braces reinforced the temporary support. The inverted arch was excavated before being removed.

Construction steps consisted of excavating part (2) and implementing the initial support around it; excavating part (3) after a certain distance (approximately $3 \mathrm{~m}$ ) behind part (2), and implementing the initial support; after lagging behind about $5 \mathrm{~m}$, excavating part (4); excavating the temporary support and removal of section 1; cleaning of the initial support base surface of the arch wall, setting up of a ring and longitudinal drainage system, and laying of waterproof boards. According to the analysis of the monitoring measurement results, after the surrounding rock and the initial support deformation were stabilized, the lining was poured in one pouring (arch wall lining was constructed at one time).

Upstairs construction: the upstairs adopted the first cutting and then the top pressure controlled blasting construction to protect the temporary support. The loop footage was controlled to 1.5 meters, and the single-stage charge was strictly controlled. The blasting vibration speed was monitored and strictly controlled. Immediately after the excavation was completed, the initial support was carried out, and each temporary support was reinforced with an 18-steel frame. The welding was fully welded to ensure quality, and a stress gauge was installed simultaneously. Strengthening monitoring measurement and arch stress value monitoring during the construction process were taken, and appropriate adjustments were made to the construction situation to ensure construction safety.

Due to the large cross section of the tunnel, traditional construction technology generally has short cycle footage. The cycle footage per cycle was not greater than $0.5 \mathrm{~m}$ for large tunnels with average daily footage of $1 \mathrm{~m}$. The small pilot tunnel is similar to a general tunnel with a smaller cross section. The circular footage reached $2 \sim 3 \mathrm{~m}$, and the daily footage reached $4 \sim 6 \mathrm{~m}$. Taking a large cross section tunnel of $100 \mathrm{~m}$ as an example, the traditional construction technology takes 100 days, and the small pilot tunnel only takes 17 to 25 working days. The construction period can be reduced to $1 / 4$, and subsequent expansion does not affect routine excavation.

4.2. Analysis of Monitoring Measurement Data Results. Monitoring and measurement are the "eyes" of safe tunnel construction. The temporary support of the first small pilot tunnel needs to be removed, and the surrounding rock and support stress of the large-section tunnel is then concentrated. The monitoring and measurement data should be accurate and reliable to correctly guide the on-site construction. Six sets of on-site measurements are listed and explained, respectively, and the deformation amount is shown in Figure 8.

Overall, the daily settlement is small, not exceeding $0.4 \mathrm{~mm}$. As time progresses, the daily settlement volume gradually decreases and stabilizes. The cumulative maximum settlement does not exceed $6 \mathrm{~mm}$, does not exceed the specified value, and meets engineering requirements. Therefore, with this excavation method, the settlement of the surrounding rock is not apparent, indicating that the impact on the displacement of the surrounding rock is small.

\section{Conclusions and Discussion}

To speed up the construction progress and avoid the increase in the construction time of the double-sided pilot pit, the lining cannot closely follow excavation and support of the 
superlarge section, which would lead to increased safety risks. Adopting the construction method consisting of a small pilot tunnel and step method reverse expansion where the small pilot tunnel passes through the super-large-section tunnel into the mainline first allows for stabilization of the tunnel when combined with the step method to reverse the expansion excavation of the small pilot tunnel. The surrounding rock conditions are first explored through the small pilot hole before excavation of the main tunnel. The main conclusions of this research are as follows:

(1) According to the theoretical analysis of elastic mechanics and the measured parameters of the tunnel in this study, in the elastic stage of the surrounding rock, the maximum displacement occurring around the tunnel is $0.027 \mathrm{~m}$. The contraction of the section is calculated to be $\sim 1.7 \mathrm{~m}^{2}$, which accounts for about $0.5 \%$ of the total tunnel excavation. When the tunnel surrounding rock is at its strength limit, the radius of the plastic zone is $2.67 \mathrm{~m}$, the displacement at the outer boundary of the plastic zone is $0.031 \mathrm{~m}$, the maximum displacement around the tunnel is $0.008 \mathrm{~m}$, and the overall reduction of the tunnel section is about $0.5 \mathrm{~m}^{2}$, which accounts for $0.1 \%$ of the total area. The overall deformation is minimal and does not affect the normal production of tunneling.

(2) According to the numerical calculation of the small pilot tunnel advance and step reverse expansion method, it can be seen that the first and second steps of construction have the most significant impact on the tunnel, and the maximum top deformation and vault deformation, respectively, account for $45.2 \%$ and $44.4 \%$ of the final settlement values. Therefore, the advance support should be strengthened during construction using the small pilot tunnel first and the step reverse expansion method. Especially during bench excavation, advance prereinforcement should be done due to the increase in the excavation section.

(3) While constructing superlarge cross section tunnels, the small pilot tunnel and step reverse expansion excavation can be adopted. After the construction of the small pilot tunnel is complete, the real situation of the super-large-section surrounding rock can be accurately grasped in advance to provide a reliable construction basis for the next step of reversely expanding the large section. This also provides a guarantee for the selection of subsequent construction methods. The construction method can save construction costs while ensuring safety, improving production efficiency, and saving enormous construction time.

The research results and proposed new excavation method can guide similar tunnel excavation engineering. However, there is still much to be done in future work. The small pilot tunnel advancement and step reverse expansion method can be optimized and form a standard. In the meantime, the working mechanism of the supporting method needs to be explored further.

\section{Data Availability}

The data used to support the findings of this study are available from the corresponding author upon request.

\section{Conflicts of Interest}

The authors declare that there are no conflicts of interest regarding the publication of this paper.

\section{References}

[1] A. Bandini, P. Berry, C. Cormio, M. Colaiori, and A. Lisardi, "Safe excavation of large section tunnels with Earth Pressure Balance Tunnel Boring Machine in gassy rock masses: the Sparvo tunnel case study," Tunnelling and Underground Space Technology, vol. 67, pp. 85-97, 2017.

[2] Z. Zhou, J. Zhao, Z. Tan, and X. Zhou, "Mechanical responses in the construction process of super-large cross-section tunnel: a case study of Gongbei tunnel," Tunnelling and Underground Space Technology, vol. 115, 2021 (in Chinese), Article ID 104044.

[3] L. Li, C. Shang, K. Chu et al., "Large-scale geo-mechanical model tests for stability assessment of super-large crosssection tunnel," Tunnelling and Underground Space Technology, vol. 109, 2021 (in Chinese), Article ID 103756.

[4] M. Wang, "Problems that need to be studied in tunnel engineering in the near future," Tunnel Construction, vol. 2, no. 2, pp. 1-5, 2020, (in Chinese).

[5] Z. Yan, Study on the Stress Path and Space Effect on Construction of Large Section Tunnel, Guangzhou. South China University of Technology, Guangzhou, China, (in Chinese), 2011.

[6] L. Chun, Study on Constructional Mechanical Responses of Highway Tunnel with Deeply-Lying and Large Cross Section, Chongqing University, Chongqing, (in Chinese), 2001.

[7] Li Dong, X. He, L. Qin, Y. Kang, D. Zhou, and C. Guo, "Stability control of super-large-span and super-shallowburied subway tunnel under crossing overpass[J]," Chinese Journal of Rock Mechanics and Engineering, vol. 32, no. S2, pp. 3636-3642, 2013, (in Chinese).

[8] Q. Wang, J. Jiang, L. Lu, C. Zhang, X. Wen, and B. Chen, "Simulation study on the influence of different excavation methods on close overlap tunnels[J]," Chinese Journal of Rock Mechanics and Engineering, vol. 32, no. 10, pp. 2079-2087, 2013, (in Chinese).

[9] W. Li, M. Sun, Y. Zhu, Z. Zhu, and Y. Li, "Arch toe stability and its control technology in soft rock tunnel construction by bench method," Chinese Journal of Rock Mechanics and Engineering, vol. 31, no. S1, pp. 2729-2737, 2012, (in Chinese).

[10] D. Zhang, Q. Tai, and F. Qian, "The safety of complex tunnel surrounding rock and its evaluation method," Chinese Journal of Rock Mechanics and Engineering, vol. 36, no. 02, pp. 270296, 2017, (in Chinese).

[11] B. Singh, R. K. Goel, and J. L. Jethwa, "Support pressure assessment in arched underground openings through poor rock masses," Engingeering Geology, vol. 2, no. 48, pp. 59-81, 1997.

[12] R. K. Goel, Correlations for Predicting Support Pressures and Closures in tunnels, Ph.D. Thesis, University India, Nagpur, 1994.

[13] R. K. Goel, J. L. Jethwa, J. L. Jethwa, and A. G. Paithankar, "Indian experiences with Q and RMR systems," Tunnelling and Underground Space Technology, vol. 10, no. 1, pp. 97-109, 1995. 
[14] N. Barton, R. Lien, and J. Lunde, "Engineering classification of rock masses for the design of tunnel support," Rock $M e$ chanics, vol. 6, no. 4, pp. 183-236, 1974.

[15] Z. T. Bienia-wski, Engineering Rock Mass Classi- Fication, pp. 32-34, John Wiley \& Sons, Znc, 1989.

[16] M. Wang, B. Guan, and C. He, "Study on the mechanical behavior of a three-lane highway tunnel under different tectonic stress," Chinese Journal of Geotechnical Engineering, vol. 20, no. 1, pp. 51-55, 1998, (in Chinese).

[17] E. Fliegner, "Mount baker tunnel in the United States-an example of large section excavation in soft soil," Tunnel Translation, vol. 1, no. 5, pp. 50-53, 1992.

[18] Y. Li and L. Wang, "Design and construction of a three-lane highway tunnel," World Tunnelling, vol. 5, pp. 33-36, 1995, (in Chinese).

[19] Y. Wang, S. Jiang, and Y. Zhang, "Research on dynamic construction mechanics of four-lane tunnel," Journal of Highway and Transport Technology, vol. 22, no. 6, pp. 134-137, 2005, (in Chinese).

[20] S. Jiang, L. Huang, and X. Hu, "Design and research of super large section highway tunnel," Chinese Journal of Underground Space and Engineering, vol. 1, no. 1, pp. 54-61, 2005, (in Chinese).

[21] L. Huang, F. Qin, and S. Gong, "Design of Yabao double hole and eight lane highway tunnel," Modern Tunnel Technology, vol. 42, no. 4, pp. 5-8, 2005, (in Chinese).

[22] C. Xia, J. Gong, Y. Tang, and H. Zhu, "Analysis and analysis of on-site monitoring of highway tunnels with large section and small spacing," Chinese Journal of Rock Mechanics and Engineering, vol. 26, no. 1, pp. 44-50, 2007, (in Chinese).

[23] Z. Sun, C. Jiao, J. Chen, and Z. Peng, "Analysis of the deformation mechanism of surrounding rock caused by the excavation of super-large cross-section tunnels with different construction methods," Railway Construction, vol. 9, pp. 60-63, 2006, (in Chinese).

[24] C. Huang, "Design and construction of Longtoushan doublehole and eight-lane highway tunnel," Railway Construction, vol. 1, pp. 52-54, 2007, (in Chinese).

[25] Li Jia and Y. Kang, "etc., Summary of some problems in the construction of large-section tunnels," Western Exploration Engineering, vol. 3, pp. 151-153, 2008, (in Chinese).

[26] F. Gan, X. Wang, Y. Kang, and Z. Zhang, "Effect of thermal cycling-dependent cracks on physical and mechanical properties of granite for enhanced geothermal system," International Journal of Rock Mechanics and Mining Sciences, vol. 134, Article ID 104476, 2020.

[27] F. Gan, Y. Kang, X.-c. Wang, Y.-q. Hu, and X.-h. Li, "Investigation on the failure characteristics and fracture classification of shale under Brazilian test conditions," Rock Mechanics and Rock Engineering, vol. 53, no. 7, pp. 3325$3340,2020$.

[28] J. Hu, H. Xie, Q. Sun, C. Li, and G. Liu, "Changes in the thermodynamic properties of alkaline granite after cyclic quenching following high temperature action," International Journal of Mining Science and Technology, vol. 31, no. 5, pp. 843-852, 2021.

[29] J. Hu, Q. Sun, and X. Pan, "Variation of mechanical properties of granite after high-temperature treatment," Arabian Journal of Geosciences, vol. 11, no. 2, p. 43, 2018.

[30] Q. Yin, J. Wu, C. Zhu et al., "The role of multiple heating and water cooling cycles on physical and mechanical responses of granite rocks," Geomechanics and Geophysics for Geo-Energy and Geo-Resources, vol. 7, no. 3, p. 69, 2021.
[31] M. Gao, J. Xie, Y. Gao et al., "Mechanical behavior of coal under different mining rates: a case study from laboratory experiments to field testing," International Journal of Mining Science and Technology, vol. 31, no. 5, pp. 825-841, 2021.

[32] M. Gao, J. Xie, J. Guo, Y. Lu, Z. He, and C. Li, "Fractal evolution and connectivity characteristics of mining-induced crack networks in coal masses at different depths," Geomechanics and Geophysics for Geo-Energy and Geo-Resources, vol. 7, no. 1, p. 9, 2021.

[33] P. Jin, Y. Hu, J. Shao, G. Zhao, X. Zhu, and C. Li, "Influence of different thermal cycling treatments on the physical, mechanical and transport properties of granite," Geothermics, vol. 78, pp. 118-128, 2019.

[34] T. Meng, R. Liu, X. Meng, D. Zhang, and Y. Hu, "Evolution of the permeability and pore structure of transversely isotropic calcareous sediments subjected to triaxial pressure and high temperature," Engineering Geology, vol. 253, pp. 27-35, 2019.

[35] S. Yang, Surrounding Rock Control Theory of Mining Roadway and Anchoring Structure Support Principle, Coal Industry Press, Beijing, (in Chinese), 2004. 